Draft: Do not share without permission from the author.

Andrea Copeland, Ph.D.

Department of Library \& Information Science

School of Informatics \& Computing

Indiana University at Indianapolis

535 W Michigan Street, IT565

Indianapolis, IN 46202

(317) 274-0114

ajapzon@iupui.edu

Public Library: A Place for the Digital Community Archive

\begin{abstract}
This article will explore the possibility of public libraries as organizational homes for digital community archives. The overarching goal is to establish a case for public libraries developing digital community archives that are participatory in nature and which emphasize born digital items rather than digitized physical items. This discussion follows my own research and experience in this area to include aspects related to personal information management, social media and the personal archive, the accidental community archive, and that public libraries focus on communities' current events and individuals rather than solely on events and persons from the past.
\end{abstract}

Introduction

The legal, technical, and organizational issues associated with the management of personal information have progressively moved out of the domain of scholarly research into the mainstream press. Major news organizations have offered online series educating readers about the challenges involved with preserving digital information. For example, National Public Radio’s All Tech Considered blog warns, “In the digital age, the family photo album fades away," and the New York Times hosts a multipart series on tips for archiving family literacy. ${ }^{\text {ii }}$ The Huffington Post has produced a series of articles on digital legacy which deals with legal and technical issues associated with digital content after one's death. ${ }^{\text {iii }}$ Also, the Library of Congress offers a personal digital archive day kit which assists libraries and other organizations in helping individuals to help themselves. ${ }^{\text {iv }}$

Initially, when approaching the issue of individuals preserving their personal digital information, I thought of public libraries as an education resource for individuals to learn about the practices necessary for long term access to their personal digital content. These ideas are explored in the article I co-authored with Deborah Barreau, "Helping people to manage and share their digital information: A role for public libraries.” I still see public libraries filling this role; however, I now see this role of helping individuals to manage and share expanding to help individuals preserve and document their place in their communities. While fulfilling this role, public libraries can become digital community archives in the process. This paper explores my own personal development of this idea based on my experience working in libraries and through my research with public library users and their digital content.

This is the author's manuscript of the article published in final edited form as:

Copeland, A. (2015). Public Library: A place for the digital community archive. Preservation, Digital Technology \& Culture, 44(1), 12-21. http://dx.doi.org/10.1515/pdtc-2015-0004 
Draft: Do not share without permission from the author.

This article will explore the potential of public libraries to become organizational homes for digital community archives. The overarching goal is to establish a case for public libraries developing digital community archives which are participatory in nature, with emphasis on born digital items rather than physical items that have been digitized.

The Development of a Proposition

\section{Initial Exploration}

In 2005, I came across an article entitled "Plenty of Room at the Bottom? Personal Digital Libraries and Collections,” by Neil Beagrie of the Library of Congress. Like the physicist Richard Feynman, Beagrie was worried about the principal parts of humanity: not atoms but actual people. In this article, he refers to these individuals as Generation C, for Content, with access to increasingly fast and inexpensive computer processing. These were individuals who had moved from not just consuming digital content but to creating, customizing and producing it.

The concerns Beagrie identified ten years ago of preserving access to personal digital information are still concerns today: security, privacy, long term access, controlling shared information, organization, and reuse. He called for more research and thought on personal digital collections and their place and relationship to digital libraries. I took his call.

As a doctoral student, I gave much thought to what would happen to the countless personal, family, and social histories contained in digital formats. Who would help people like my father, my friends, my mechanic, my physician, my hairstylist with documenting and preserving this information? I talked with everybody I could about their digital 'stuff' - no one had a clue as to what to do other than to try to remember to back it up to CDs or an external hard drive... when they had time.

Unfortunately, public libraries do not offer digital repositories for their constituents' digital creations in the way that academic and corporate libraries do. Nor it is typical for public libraries to provide consultation on digital preservation or information organizational practices. Prior to starting doctoral studies at Drexel University, I worked at the NASA Goddard Library in Greenbelt, Maryland. At that time, the library was active in helping to create systems that would capture and organize the digital intellectual output of the Goddard Community for preservation and reuse over the long term (Anderson, Hodge \& Japzon).

Given my professional background and prior research on public libraries and communities, I thought about the potential for public libraries to be a digital preservation resource for their users. Currently, the typical public library user or the individual not associated with a sophisticated pro-active research minded institution is left to the mercy of Best Buy employees, the friend or relative who works in IT, and increasingly the corporate entities lurking in the cloud - Google, Yahoo, and Facebook.

The personal computing environment (I am including digital devices and cloud computing) lacks robust information organizational tools and a preservation infrastructure. Given these inherent limitations, I decided to study what public library users did to organize and protect their personal digital information for long term use. 
From this study of 26 public library users, I learned the following: the primary preservation strategy of participants was to back their data up in one or more places, without differentiating between items of great value and little to no value (Copeland, “Analysis”). The participants did not try to build collections of particular information items based on appraisal and selection decisions. Time simply did not permit this level of attention at the item level. Further, individuals expressed anxiety about their inability to anticipate all of their future information needs (Bruce) and feared if they did not continue to save all their information, they might regret it later.

Affective, cognitive, and technical influences inform the processes individuals have developed to deal with their digital content. The most common affective response was anger and sorrow over lost content, which often motivated obsessive backing up practices. The cognitive strategies included organizing hundreds to thousands of files in folders and subfolders with ambiguous headings such as "Research," "Current Project," and "Family Photos." With regards to technology, the participants allowed their devices to determine file formats rather than researching and determining what was best for long term access and reuse.

Also, I found that the participants' most important personal digital information had been shared with others. Those participants who suffered a total system failure could recover their most valuable digital information because, through sharing information with others, they had copies stored in their email, complete with descriptive metadata and transaction stamps.

\section{Co-created Community Repositories}

During this research, I began exploring the idea of co-created community repositories (Japzon). I proposed a model that would allow library users and librarians to work together to create community repositories, each sharing their own expertise and learning from one another.

For libraries and other memory organizations to create a sustainable infrastructure for digital preservation, they must collaborate with each other, create interoperable systems, and develop standards for creation, preservation and reuse. Who does the individual collaborate with to create a sustainable infrastructure of support for their personal digital content? Could individuals be a part of formal efforts to preserve our collective cultural digital heritage?

Could public libraries work with their constituents to create community repositories for the preservation of personal information, which also contributes to social and cultural histories?

Public libraries are potentially excellent providers of education to individuals regarding the creation and preservation of personal digital collections. Firstly, public libraries are either gaining or creating state-ofthe-art knowledge as they develop and maintain their own digital collections. Secondly, public libraries are a vital part of communities and of the information economy, and as such are in position to create connections between the two. Thirdly, public libraries already serve the role of educating users through a diversity of information skills programs. Lastly, public libraries are creating digital collections of local significance through the digitization of local history documents that could easily attract the involvement of community members and encourage the development of born digital collections.

Further, individuals are excellent resources for the creation of community collections. They provide knowledge of local history, customs and events and often have a personal interest in supporting community organizations. From the museum science community, Russo and Watkins have described 
Draft: Do not share without permission from the author.

"community co-creation" as cultural institutions and communities working together to create digital content, each benefiting and learning from the other's expertise and experience. In the creation of cocreated community repositories, library and information professionals working through their organizations would provide a technical infrastructure and technical expertise in collection development and maintenance. Community members would provide the knowledge that supports content development and contribute personal digital content from their own collections.

\section{Case Study: Eckhart Public Library}

My first effort at creating a community repository was somewhat successful. The Eckhart Public Library in Auburn, Indiana agreed to work with me on this idea. ${ }^{\mathrm{v}}$ We invited ten diverse community members to make contributions of personal information to their existing genealogy center. Participants were asked to contribute items in both digital and physical formats that represented their connection to the Auburn community. Sue McKemmish in her paper, "Evidence of Me," discusses the point at which "I becomes we;" this point speaks to the social as well as cultural importance of personal information. The effort was only somewhat successful because all of the items brought to the library were physical, and I wanted to work in the digital realm. However, the librarians were thrilled with the information and artifacts they received. Most items were scanned, made digital and added to their digital collections. Many materials were donated to the library.

I should have seen the deluge of physical items coming. As a part of the study with public library users, I explored values associated with both their physical and digital information. When I asked participants to name one physical and one digital information item of great value to them, all 26 immediately described a physical item but it was nearly impossible for them to identify just one digital item of great value. With digital information, it seemed to be an all or nothing proposition. All of their digital items were valuable to them, or collections of photos or writings were valuable, but no one item was cited as having great value. This perception is counter to the type of thinking needed to build collections, where selection and appraisal are essential to information organization and preservation. This is an area where librarians and other information professionals have a great deal to offer their constituents with regards to building personal and community based collections. It is not possible for everything to be saved and everything is not valuable. This is a reality that libraries and archives of all types of have had to deal with long before the deluge of digital information (Cox).

What was successful for me was the confirmation that community history lived and breathed in the minds of the community members. There were great stories to tell, stories worthy of documenting formally and sharing with others. The items that the ten individuals submitted to the library were tangible representations of their local high school, family members, homes, cars, jobs, and community organizations (churches, the library, sports leagues, and lions club). Also submitted were artifacts representing formal recognition. For example, one war veteran brought in a purple heart.

Among the treasures unearthed in this process was the home archive of the beloved retired high school baseball coach. Bill Jones coached for 30 years for the DeKalb County High School. When I met him, he was a scout for the Detroit Tigers. Sadly, he died within a year of meeting with us at the library. He donated quite possibly one of the most meticulously kept records of a high school baseball team in existence. It contained programs and stats from every season and numerous newspaper articles, including one photo from the local paper of Bill running around the town center in his underwear, a feat he promised to perform if his team won the state championship. There were photos of every one of his 
Draft: Do not share without permission from the author.

players that went pro in their team uniforms. There were many volumes of local guys making good in professional sports. I started to think of him as the John Wooden of baseball.

Bill Jones' home archive is an excellent example of the type of content belonging to an individual that would also be of great value to community and social history. But where does it belong? A university archive? A historical society? A museum or a public library? Flickr? Google Plus? I would suggest the public library, but also online and integrated with other digital cultural heritage collections at the collection level; ideally, it would be placed at the item or metadata level as well.

\section{Social Media and the Personal Archive}

Generation $\mathrm{C}$ is sharing and storing items on social networking sites numbering in the billions. Much of the content is self-produced, from creative writings to family photographs to garage-band covers to clips of home-made "how-to" demonstrations. The sites, blogs and pages are often made available through commercial providers. Instead of taking the shape of unique and collectible scrapbooks of old, personal archives are being formed in the Facebook model (Tucker, Ott \& Buckler; Good). For the most part, memory organizations are not involved in the process of collecting and preserving these billions of words, images, sounds and motion media created and stored digitally by millions of individuals. My next study was an attempt to begin to identify the types of information shared via these media sites that might also have value to our cultural historical record.

If the mountain won't come to Muhammad then Muhammad must go to the mountain. I went to the mountain, or Facebook. Since study participants were inclined to bring in physical information items to the library, I needed to go with them to their stores of digital information. In this study, the participants, 30 librarians and information professionals and 30 public library users, discuss photos they had shared with others on the web and photos shared with them as well as some as I wanted to share (Copeland, "The use”). All the participants were from the Indianapolis metropolitan area and users of the city's public library. The participants and I sat in front of a laptop and looked at their photos, mostly Facebook, and discussed which photos were valuable to them, to their families, and to society. I asked them which ones belonged in public library digital collections and why.

Given the importance of equitable collaboration and respectful cooperation among formal government agencies, individuals, and local or grassroots community organizations, this study attempts to understand the level of agreement between librarians and library users with regards to the types of user-generated content they thought that libraries should or could collect. Often, the two groups agreed. Without agreement, the potential for co-creation would be greatly limited.

\section{Social Media and Accidental Community Archives}

In Clay Shirky’s book, “Here Comes Everybody: The power of organizing without Organizations,” he writes about Generation $\mathrm{C}$ and how they are making connections and building collections of social significance outside of formal institutions. Shirky provides several examples of individuals who have done this. The story about the Mermaid Parade that takes place every year in Brooklyn, New York stands out as particularly relevant to this discussion. He writes that, prior to Flickr, no effort had ever been made to document this annual event, so significant to Coney Island's history and to many New Yorkers 
Draft: Do not share without permission from the author.

personally. The effort made through Flickr was not a conscious collective effort to document this community event; rather, individuals attending the parade simply posted their photos of the spectacle and tagged them "Mermaid Parade.” One only has to deploy a keyword search to find many documents lending evidence that this event took place. Could this be construed as an archive, at least an accidental one?

The Social Life of Information by John Seely Brown and John Duguid was published 10 years before Shirky's book. They assert that the technologically empowered individual will do away with the need for social organizations; that individuals can just work outside of their strictures to create their own means of doing just about anything they desire....to a point. The authors put forth that informal information organizations can grow only so large before formality, rules, guidelines, and polices are needed to keep them going, for their own survival. This is why I am not concerned about libraries or archives being replaced by technologically empowered individuals or corporate entities like Google. Simply put, keyword searching and archives created "accidentally” don't scale over time or space. For example, who is worried about long term access to the Mermaid Parade photo archive, the rights issues associated with each of the images, the veracity of the metadata, and the comprehensiveness and consistency of the tags utilized? Not Flickr. And why should Flickr be? It is not a memory organization; i.e., it does not have any responsibility to preserve artifacts associated with public memory. It's a photo sharing site with a global audience. My question then is do memory organizations bear the responsibility generally and public libraries specifically of documenting these types of community events and preserving access to document-based representations of community over the long term?

While Indianapolis does not have a Mermaid Parade, it did host Super Bowl XLVI in 2012. This was a community event of the grandest kind. Residents' lives were impacted for more than a year in preparation for the big event, which, incidentally, many could not afford to attend. Downtown neighborhoods were revitalized, hotels built, roads improved and the Super Bowl Village was born in the months leading up to the event. The city as a whole wanted Indianapolis to look good on the national screen, even those not interested in professional sports. The event's success fostered pride in Hoosiers statewide. How does one capture the 2012 Super Bowl? Beyond, say, the Flickr experience? Again, I would suggest public libraries and digital archives have a vital role in preserving the collective recall of community-wide events.

On Flickr's website one will find numerous photos documenting this event from the point of view of individuals in the Indianapolis community. I selected one of these images to discuss with the study participants. ${ }^{\text {vi }}$ Overwhelmingly, this photo was considered important for its documentation of place, community, and the event. Some saw this as a localized, Indianapolis-specific event and others as a national event. The participants were in Indianapolis, it is part of their personal history, and it is in the collective memory. Many of the participants took the exact same picture. When looking at the photograph, one can see the many heads of the individuals trying for the same shot. Almost all participants felt strongly that this photo belonged in a public library digital collection. Currently, no place exists but Flickr and other similar photo sharing sites to assemble these types of images, and the living narrative that captures this experience.

\section{Public Libraries and Digital Community Archives}


Draft: Do not share without permission from the author.

This study also explored the idea of the public library becoming a living digital community archive that documents and preserves the local heritage of its community as it is happening, rather than an after the fact historical. Reason being, digital content, preservation and creation must be considered at the same time. If there is a past to be studied that is primarily digital in format, then archival considerations need to coexist with creation.

The participants and I examined photographs representing their present lives or their recent histories which, like most recent information, resides in a digital format only. The latest comprehensive study on information creation, completed in 2003, found that $92 \%$ of all new information was stored digitally (Lyman \& Varian). Eleven years later this percentage is no doubt greater. Libraries of all types have spent a great deal of resources scanning photographs and physical artifacts that represent the community events that once were. In doing so, they have been able to share collections of local significance with the world this is a great service to scholarship and life-long learning alike. While I support, this type of digital collection creation, I also feel there is a need for libraries to collect born digital information of significance for the reasons previously mentioned and because the ease of content creation and distribution in the digital realm has exploded the amount of information. The same study found that all forms of new information doubled from 2000 to 2003 doubled. With ease and convenience comes waste, therefore the skills of librarians and archivists are needed more than ever to help individuals and communities make selection and appraisal decisions that will best document and preserve their communities' histories.

It has been speculated that every time there is been a shift in the predominance of one form of communication, a significant amount of new information is lost. In shifting from oral traditions, to manuscripts, to printing presses, and now to digital communications, records documenting evidence of human experience are lost in the transition as we learn to organize and preserve information in a new format. Earlier and continued efforts by the Internet Archive have tried to prevent this from happening by harvesting and storing content published openly to the web. ${ }^{\text {vii }}$ A search of their Way Back Machine will show you just how much of this content has been lost to technological obsolescence. As with print and other tangible materials, this job is too large for one organization alone to organize and make accessible.

Moving from ideas to Implementation

\section{Challenges}

Foremost among the challenges faced by public libraries is the fact that public sector resources are dwindling, and as a result public library budgets have tightened. In many areas of the country, public libraries have increasingly faced budget cuts, decreasing hours and reduction in staffing (Davis; Lyons). As a result, there is little time or money for innovation or technology infrastructure changes. Currently, public libraries are faced with economic and technological challenges related to supporting both digital 
Draft: Do not share without permission from the author.

and print access to content, particularly ebooks (Brynko) and technology hardware and software required to meet the basic digital information needs of their communities (America Library Association). As more library content is acquired online and used remotely, librarians will continue to explore new ways to help users create, connect with and experience community (Lankes; Neiburger). Engaging communities in the creation of born digital collections is one possible means of extending public library resources, limited as they are, to meet user expectations regarding participatory information creation, use, and capture.

\section{Resources for Implementation}

There is an abundance of resources to guide the practitioner in the process of creating and caring for digital collections. The goal of this paper is to suggest new ways of thinking about public libraries and how they engage with individuals in the creation and preservation of personal history which is also relevant to community and social history. The following resources mostly reflect the efforts of research libraries that have had the funds to spend on the development of systems and practices related to building digital collections. Many of the valuable lessons they have learned are freely available on the web. Cornell University provides a wealth training materials and courses related to digital preservation management. Yale University provides resources related to born digital resources. ${ }^{\text {viii }}$ Library of Congress offers a wealth of resources to aid in the creation and preservation of digital collections. ${ }^{\mathrm{ix}}$ The Digital Curation Centre offers an online reference manual for digital curation. ${ }^{\mathrm{x}}$ OCLC's WebJunction provides an extensive list of online resources to aid in the production of digitized collections. ${ }^{x i}$ For those interested in a textbook, Harvey Ross provides of one of the most accessible how-to-guides for curating digital collections covering the full range of organization and technical issues.

\section{Collaboration}

Collaboration with other libraries and agencies is perhaps the best way for public libraries to explore the development of community created digital collections and archives. This level of commitment will likely stem from the state libraries. One of the main purposes of LSTA funds is to support major technological initiatives in libraries throughout the United States. For example, the Indiana State Library provides access to the Indiana Memory Collection, a CONTENTdm supported repository, for all libraries and museums throughout the state to use to create and share digital collections. ${ }^{\mathrm{xii}}$ A next step would be for the State Library to extend this repository for use in community created collections. Another example of how this might be done is through public libraries working with academic libraries to create and store these collections. For example, the California Digital Library, a collaborative effort of the California state universities in partnership with the California State Library, created the California Local Digital History Resources Project. ${ }^{\text {xiii }}$ This project provides a "solution in a box" for all types of libraries to become capable of creating digital primary resource collections. Collaborations like this one will increase awareness, access, and use of digital collections through shared expertise and resources.

\section{Volunteers}

If the technical aspects of creating community repositories could be achieved economically through collaboration, the staff time needed for these types of endeavors to be successful would be considerable. Volunteers have been used for many crowd-sourced social and local history digital collections. One interesting example is: The AIDS Memorial Quilt, in which the entire quilt was digitized with volunteers attributing searchable metadata to each quilt including any text written on the quilt. ${ }^{\text {xiv }}$ A second example 
Draft: Do not share without permission from the author.

is The New York Public Library's “What's on the Menu?” digital project, which involves volunteers transcribing thousands of menus dating back to the 1840s. ${ }^{\mathrm{xv}}$ The typeface on both the quilts and the menus were not recognizable by OCR and could have only been transcribed using volunteers, as the cost to have staff do this would have been prohibitive. Using volunteers in this manner requires little training and management. However, using volunteers for more highly skilled tasks might require more time and effort to organize with less control over the end product. Leonard provides an overview of both positive and negative aspects of using volunteers for archival work. Collections based on community member contributed content inherently shift the selection and acquisition functions to volunteers. Even so, educational, organizational, and technical management would require the attention of paid professional staff.

\section{What to create?}

Creating a sense of place is one goal to be achieved in describing and documenting communities. Places are most often described by the objects and events, both man-made and natural, which happen within a given space (Tuan). Ultimately, the community and librarians working together should define the scope of the community created collections and archives. Social interests and community values are descriptive of communities as well. Halbwachs describes this as the effect of place and group imprinting upon one another in relation to a spatial framework (in this case, community) in which events occur: life events are merged with objects, buildings, things; one is not realized without the other. To fully document events and objects that occur within a community space, representations of events and objects need to be preserved along with the experience of these events and objects as described by individual community members in some collective manner. This type of documentation is abundantly apparent in social media sites. Public libraries are beginning to use Facebook as a means of collecting and sharing community experiences (Lenstra), which could be viewed as a conceptual first step towards building community archives created as public good and within a preservation infrastructure.

The next phase of my research will attempt to create a prototypical community archival application that functions both independently as well as in conjunction with a shared preservation repository. I chose the bicycle movement in Indianapolis to test the prototype application among the many possible everyday community issues because the geographic and mobile nature of the phenomenon is likely to expose the transitory and elusive nature of trying to capture both place-bound and digital history as it is happening. Information regarding the movement is current, digital, and widely distributed. Over the past several years, cycling in Indianapolis has gained a great deal of momentum. The cycling movement has brought about economic growth, improvement to the general air quality, and personal health gains. The city's cyclists would be the primary contributors to this community archive and, secondarily, those individuals who have benefitted and lost due to the infrastructure changes brought about by the construction of 74 miles of bike lanes.

Through this effort, I hope to identify the kinds of expertise, resources, policies, social understanding, and technology needed to successfully build community heritage archives in public libraries and for others seeking preservation of personal or community histories. The Omeka application, an open source content repository, will be adapted to include the ingestion of images and other born digital content from diverse access points. ${ }^{\text {xvi }}$ Further, it will be evaluated for its potential as a basis for creating a tool that will allow for easy customization by different public libraries, community groups and individuals. 
Draft: Do not share without permission from the author.

The planning for this project will be a collaborative effort of several departments on campus, community members, and government officials. The key campus partnerships would involve faculty in the Schools of Informatics and Computing and Liberal Arts (specifically the departments of Library and Information Science, Human Centered Computing, and History); researchers at the Polis Center (which provides geographic and visual data for local community analysis), and members of the University Library's Digital Scholarship Team, who will connect the Omeka application to The Digital Preservation Network through the library's existing technology infrastructure. ${ }^{\text {xvii }}$ Community partners would involve all the community members who wish to share their experiences of the cycling infrastructure changes, the Indianapolis Public Library, and the Mayor's Office of Sustainability.

It is my hope that this collaborative effort will illustrate the need for a Center for Digital Personal and Community Heritage Informatics. A center would provide a vehicle for research, education and collaboration among individuals, public libraries, community groups, and scholars who wish to work and research in these areas. The center would help to bring individuals together who are concerned about public memory and cultural heritage in the digital realm that prioritizes communities and individuals over commercial and profit-driven entities.

\section{Future Direction}

Start with the digital, not the physical. With the lion's share of new information being born digitally, memory organizations will have to extend current efforts of scanning paper-based evidence to document community history to include digitally created documents. Social media sites provide good examples of how this might be done and provide examples of the kinds of content individuals value for sharing and documenting personal histories as well as social (Terras).There is much for memory organizations to gain from the cultural and technical experience of Facebook and Flickr. At the same time, there is much that memory organizations can offer to our collective digital cultural heritage that is currently untapped.

Along these lines, Tom Lipinski and I evaluated the terms of service for several social media sites to see if any would support the community archive building activities of public libraries (Lipinski \& Copeland). While the terms of service offered much to be considered in the crafting of such terms for digital community archives, the sites themselves could not be used to support the archives. Among the reasons, the sites do not provide for digital preservation that would provide long term access to content, nor do they provide for First Amendment protection which public libraries must consider.

With the cycling community archive, there is the potential to explore capturing valuable social media content while also providing an infrastructure of support that would ensure organization and long term access. Many cyclists are already using social media to document the very aspects of the city's infrastructure changes I wish to capture. Through a contributor registration process, it would be possible to devise a means for individuals wishing to contribute to the community archive to do so without changing their existing use of social media. Through the registration process, contributors could grant the archive permission to capture, store and use their content. Also, contributors would be made aware of tagging protocols in order to facilitate the archive harvesting their content from a variety of social media sites. In this way, contributors would not have to change their usual information sharing behaviors and the archive could capture socially relevant content posted to social media sites. 
Draft: Do not share without permission from the author.

\section{Conclusion}

Recently, as I was presenting at the Personal Digital Archives conference, I shared the story of Bill Jones, of Auburn, Indiana high school baseball coaching fame. An audience member pointed out that people rarely spend their whole lives in one community anymore and that communities are fluid entities becoming more difficult to document, define, and confine. She wanted to know how communities and the individuals that make up those communities were to participate in building community collections when their place in that community might not be as clearly defined as that of Bill Jones. This adds a challenge which I believe that the fluid and dynamic natures of digital information and public libraries can help to solve. Hopefully, the cycling community archive project will yield some insight into how to begin to address documenting the dynamic nature of communities.

As a library and information science educator, I feel that in order for this challenge to be met, the curriculum will need to address the types of technical, legal, social and historical factors that would promote the creation of digital community archives within public libraries. It has often been said the digital information revolution has made the archivist more concerned about providing community access than ever before and the librarian more concerned about preservation and long term access issues. Hopefully these concerns will bring archivists, librarians, and educators together to create communityinclusive digital collections and archives that will remain relevant and accessible over the long term. This could be accomplished through memory organizations partnering with each other, bringing diverse skill sets together as well as through public libraries hiring community archivists.

One could assert the three main purposes of a public library are to educate, to entertain, and to preserve. Through the years there has been an evolution from primary emphasis on education, giving users what they ought to be reading, to more of a focus on entertainment, valuing what users want to read, namely fiction (Ross). Public libraries have placed much less emphasis on preservation and as a result lack the resources necessary to create or to connect to a preservation infrastructure. However, they would be the logical institutions to develop the theoretical, technical and practical framework necessary to connect to a, perhaps state or national, preservation infrastructure to archive local heritage documentation. Further with initiatives like community-created digital repositories, library as publisher, and makerspaces, "to create" could become a fourth important role for public libraries to fulfill in their communities.

\section{References}

American Library Association. "Public Library Funding and Technology Access Study, 2010-11.” http://www.ala.org/research/initiatives/plftas/2010_2011\#final\%20report (accessed 8/15/14).

Anderson, Nikkia, Gail Hodge, and Andrea Japzon. "Harnessing NASA Goddard's grey literature: The power of a repository framework.” The Grey Journal 3.3 (2007): 154-158.

Beagrie, Neil. "Plenty of room at the bottom? Personal digital libraries and collections.” D-Lib Magazine 11.6 (2005, June). http://www.dlib.org/dlib/june05/beagrie/06beagrie.html (accessed 8/15/14).

Brown, John S. \& Duguid, Paul. The Social Life of Personal Information. Boston: Harvard Business Review Press, 2000. 
Draft: Do not share without permission from the author.

Bruce, Harry. “Personal, anticipated information need.” Information Research 10.3 (2005, April). http://informationr.net/ir/10-3/paper232 (accessed on 8/15/14).

Brynko, Barbara. “Libraries: Coping With 'Digital Squeeze'.” Information Today 29.4 (2012): 1-36.

Copeland, Andrea. "The use of personal value estimations to select images for preservation in public library digital collections.” Future Internet 6 (2014): 359-377. http://www.mdpi.com/19995903/6/2/359 (accessed on 8/15/14).

---. “Analysis of public library users’ digital preservation practices.” Journal of the American Society for Information Science \& Technology 62.7 (2011): 1288-1300.

Copeland, Andrea and Barreau, Deborah. "Helping people to manage and share their digital information: A role for public libraries.” Library Trends 59.4 (2011): 637-649.

Cox, Richard. Vandals in the Stacks?: A Response to Nicholson Baker's Assault on Libraries. Santa Barbara, Praeger, 2002.

Davis, Denise M. “Challenges to sustaining library technology in a tough economy.” Public Libraries 48.4 (2009): 12-17.

Good, Katie D. "From scrapbook to Facebook: A history of personal media assemblage and archives.” New Media \& Society 15.4 (2013): 557-573.

Halbwachs, Maurice. “Space and the collective memory.” In The Collective Memory. New York: Harper \& Row, 1980.

Japzon, Andrea. A model of and support for a digital preservation infrastructure that connects individuals to libraries. Proceedings of the World Library and Information Congress: $74^{\text {th }}$ General Conference and Council (2008). http://www.ifla.org/IV/ifla74/papers/084-Japzon-en.pdf (accessed 8/14/15).

Lankes, R. David. The Atlas of New Librarianship. Boston: MIT Press, 2012.

Lenstra, Noah. (2014). “Cyberorganizing everyday heritage in and around public libraries: An exploratory study." Public Library Quarterly 33.1(2014): 1-22.

Lipinski, Tomas and Copeland, Andrea. "Look before you License: The Use of Public Sharing Websites in building Patron Initiated Public Library Repositories.” Preservation, Digital Technology \& Culture 42.4 (2013): 174-198.

Lyman, Peter. \& Varian, Hal. "How much information 2003?” http://www2.sims.berkeley.edu/research/projects/how-much-info-2003/ (accessed 8/14/15).

Lyons, Ray. (2013). "Rainy Day Statistics: U.S. Public Libraries and the Great Recession.” Public Library Quarterly 32.2 (2013): 97-118.

McKemmish, Sue. “Evidence of Me ...” Archives and Manuscripts 24.1 (1996, May): 28-45. 
Draft: Do not share without permission from the author.

Neiburger, Eli. (2012). “The end of the public library. (As we knew it)?” In Book: A futurist’s manifesto, edited by Hugh McGuire \& Brian O’Leary. Boston: O’Reilly (2012): 269-275.

Ross, Catherine. “Readers' advisory service in North American public libraries: 1870-2005; A history and critical analysis (Review)." Library Quarterly 78.4 (2008): 490-493.

Ross, Harvey. Digital Curation: A How-to-do-it Manual. New York: Neal Schulman Publishers Inc, 2010.

Russo, Angelina. \& Watkins, Jerry. "Digital cultural communication: Audience and remediation.” In Theorizing Digital Cultural Heritage edited by F. Cameron \& S. Kenderdine. Cambridge, MA: MIT Press (2007): 149-164.

Shirky, Clay. Here Comes Everybody: The Power of Organizing without Organizations. New York: Penguin Press, 2008.

Terras, Melissa. “The Digital Wunderkammer: Flickr as Platform for Amateur Cultural and Heritage Content.” Library Trends 59.4 (2011): 686-706.

Tuan, Yi-Fu. Space and Place. Minneapolis: University of Minnesota Press, 1977.

Tucker, Susan, Katherine Ott, and Patricia Buckler. The Scrapbook in American Life. Philadelphia: Temple University Press, 2006.

\footnotetext{
' Glenn, H. (2013, July 13). In the digital age, the family photo album fades away. National Public Radio, All Things Considered, Tech, Culture, and Connections Blog. Retrieved from http://www.npr.org/blogs/alltechconsidered/2013/07/25/205425676/preserving-family-photos-in-digital-age. ${ }^{i i}$ Lyons, B. (2013, May 29). Tips on archiving family history, part 1. The New York Times. Retrieved from http://www.nytimes.com/2013/05/29/booming/tips-on-archiving-family-history-part-1.html?_r=1\&

${ }^{i i i}$ Huffington Post. Series of articles on Digital Legacy. http://www.huffingtonpost.com/tag/digital-legacy/.

${ }^{i v}$ Library of Congress. Personal digital archiving day kit. Retrieved from http://digitalpreservation.gov/personalarchiving/padKit/index.html.

${ }^{v}$ Eckhart Public Library. The Willennar Genealogy Center. http://www.epl.lib.in.us/genealogy.php

${ }^{v i}$ Billue, Curtis. Super Bowl XLVI, Monument Circle, Indianapolis display. Retrieved from http://www.flickr.com/photos/curtispic/6815050069/

vii Internet Archive. https://archive.org/index.php
} 
viii Digital Preservation Management: Implementing short-term strategies for long-term problems. http://www.dpworkshop.org/

ix The Library of Congress: Digital Preservation. http://www.digitalpreservation.gov/

x DCC Curation Reference Manual. http://www.dcc.ac.uk/resources/curation-reference-manual/

${ }^{x i}$ Best Practices and Planning for Digitization Projects.

http://www.webjunction.org/documents/webjunction/Best_Practices_and_Planning_for_Digitization_Projects.html

xii Indiana Memory. https://digital.library.in.gov/

xiii California Local Digital History Resources Project. http://listserv.califa.org/lhdrp.php

xiv The AIDS Memorial Quilt. Search the Quilt. http://www.aidsquilt.org/view-the-quilt/search-the-quilt

xv The New York Public Library. What's on the Menu? http://menus.nypl.org/

xvi Omeka. http://omeka.org/

xvii The Digital Preservation Network: http://www.dpn.org/ 